\title{
Blood Pressure Response to Cold Stress in Black Cameroonian Adults
}

\author{
Sylvie Ndongo Amougou ${ }^{1,2 *}$, Hamadou Ba1,3, Chris Nadège Nganou-Gnindjion, \\ Dieudonné Danwe' ${ }^{1}$, Jingi Musa Ahmadou' ${ }^{2}$, Liliane Kuate Mfeukeu ${ }^{1,3}$, \\ Jérome Hilaire Boomhbi ${ }^{3}$, Christian Ngongang Ouankou' ${ }^{2}$, Samuel Kingue ${ }^{1,3,4}$
}

${ }^{1}$ Department of Internal Medicine, Faculty of Medicine and Biomedical Sciences, University of Yaoundé I, Yaoundé, Cameroon ${ }^{2}$ University Teaching Hospital, Yaoundé, Cameroon

${ }^{3}$ Yaoundé General Hospital, Yaoundé, Cameroon

${ }^{4}$ Ministry of Public Health, Yaoundé, Cameroon

Email: *ndongoamougou@yahoo.fr

How to cite this paper: Amougou, S.N., Ba, H., Nganou-Gnindjio, C.N., Danwe, D., Ahmadou, J.M., Mfeukeu, L.K., Boomhbi, J.H., Ouankou, C.N. and Kingue, S. (2017) Blood Pressure Response to Cold Stress in Black Cameroonian Adults. Open Access Library Journal, 4: e4111.

https://doi.org/10.4236/oalib.1104111

Received: November 2, 2017

Accepted: December 3, 2017

Published: December 6, 2017

Copyright ( $\odot 2017$ by authors and Open Access Library Inc.

This work is licensed under the Creative Commons Attribution International License (CC BY 4.0).

http://creativecommons.org/licenses/by/4.0/

\begin{abstract}
Introduction: The cold test is known as a predictor of essential hypertension. The hemodynamic response to this test has rarely been studied in black African adults. Black Africans also suffer cold stress. But whether they suffer it the same way as other populations is still to be determined. Equipment and Method: We studied the response of blood pressure (BP) during the cold test in 62 black normotensive adults and hypertensive Cameroonians aged between 21 and 59 years. Those with an increase in systolic blood pressure (SBP) $>20$ $\mathrm{mmHg}$ and/or diastolic blood pressure $>15 \mathrm{mmHg}$ were considered to be hyper-reactors. Results: SBP increased significantly in hyper-reactors compared with normo-reactors in both hypertensive and normotensive subjects (176 \pm 20 vs. $154 \pm 11, \mathrm{p}=0.01$ and $148 \pm 17$ vs. $125 \pm 11, \mathrm{p}<0.001$, respectively) and this increment persisted up to two minutes after the end of the stress exposure although the difference was no more statistically significant. We found the same result for the DBP $(111 \pm 13$ vs. $99 \pm 10, p=0.04$ and $95 \pm 11$ vs. $81 \pm 10, \mathrm{p}=0.001$, respectively). However, the DBP stayed higher in hyper reactors compared to normal reactors in the normotensive group up to four minutes after cessation of the stress exposure. The recovery time of the baseline BP was considerably longer in hyper reactors compared with the normal reactors $(2.1 \pm 0.9$ vs. $1.1 \pm 0.4$ minutes, $\mathrm{p}=0.01$ and 1.9 \pm 1.0 vs. $1.3 \pm 0.5$ minutes, $\mathrm{p}=0.03$ respectively in hypertensive and normotensive). Conclusion: Hyper reactors in the cold test have a more pronounced and prolonged reactivity. They are thus predisposed to develop hypertension.
\end{abstract}




\section{Subject Areas}

Cardiology

\section{Keywords}

Blood Pressure, Cold Test, Black Cameroonian

\section{Introduction}

High blood pressure (HBP) is a major public health concern in the world in general and in Africa most especially. Its prevalence on the continent was $46 \%$ in 2008 and was the highest in the world according to the World Health Organization (WHO) [1]. It is constantly growing with the Westernization of lifestyles. Kearney et al. estimated in 2012 that by 2025, the number of hypertensives in sub-Saharan Africa will be double the number in 2000 [2].

HBP is one of the major risk factors for cardiovascular disease. These were responsible for $31 \%$ of global mortality in 2015 and three-quarters of these deaths occurred in low- and middle-income countries [1]. Preventing hypertension in order to reduce morbidity and mortality is therefore an important public health challenge, especially in low- and middle-income countries such as those in sub-Saharan Africa. Essential hypertension, to which no single cause can be attributed, accounts for the majority of hypertension cases $(\approx 90 \%)$ [3]. Its pathophysiology is complex and involves genetic, environmental and behavioral factors that make individuals susceptible to the development thereof. The cold test, an experimental human stress induction technique used for the first time by Hines and Brown in 1936, would predict the onset of hypertension [4] [5]. By identifying individuals at risk of having a HBP, we can carry out preventive activities which would be beneficial not only to the patient but also to the public health. People prone to high blood pressure tend not only to have exaggerated responsiveness to stress, but this reaction is prolonged over time [6]. To our knowledge, few studies have evaluated hemodynamic response in African black subjects resulting from exposure to stress. We conducted this study to determine the pattern of hemodynamic response of black Cameroonian adults after their exposure to cold stress.

\section{Equipment and Method}

We carried out a comparative study from 1 December 2016 to 31 April 2017 at the Yaoundé University Hospital (CHUY). The study was approved by the Institutional Committee for Research Ethics (CIER) of the Faculty of Medicine and Biomedical Sciences (FMSB) of the University of Yaounde I (UYI). We obtained authorization from the CHUY branch and each participant gave us his informed consent. We included hypertensive patients not on antihypertensive drugs seen in outpatient consultation, and clinically healthy normotensive subjects aged 
between 18 and 60 years who accepted to participate to this study. The cold test was used to induce stress to all participants. Subjects with Grade 3 hypertension, signs of secondary hypertension, pregnant women and those with a history of heart disease, bronchopneumonia, chronic kidney disease or peripheral neuropathy were excluded from the study. The cold test was used to induce stress and was carried out as follows: after 15 minutes of rest in supine position, the blood pressure (BP) was measured three times at 1 minute interval and the average of the three measurements was considered as the basic BP. The subject was then invited to immerse his left hand in ice water $\left(3-6^{\circ} \mathrm{C}\right)$ for 1 minute. Finally, BP was measured at $0,1,2,3$ and 4 minutes after hand extraction from cold water. The subjects were respondents when there was an increase in SBP $>20 \mathrm{mmHg}$ and/or DBP $>15 \mathrm{mmHg}$ during the cold test. The restoration time was the time between the end of the hand immersion and the return of the BP to the basic values $( \pm 5 \mathrm{mmHg})$. Statistical analyzes were carried out using the Statistical Package for Social Sciences (SPSS) software version 20.0. The results were expressed as \pm average Standard Deviation. The standard Student test was used to compare the averages. The threshold of statistical significance was set for $\mathrm{p}<0.05$.

\section{Results}

Overall, 62 patients were enrolled in this study, 31 of whom were normotensive and 31 hypertensive. Table 1 shows the baseline characteristics of the participants. The average age was $42 \pm 9$ years for normotensive patients and $45 \pm 9$ years for hypertensive patients. The sex ratio was 0.48. At baseline, the mean Systolic Blood Pressure (SBP), Diastolic Blood Pressure (DBP), Heart Rate (HR) as well as weight and Body Mass Index (BMI) were significantly higher in hypertensive patients. Figure 1 and Figure 2 show the SBP variation at baseline and during the cold pressor test between hyper reactors and normal reactors

Table 1. Baseline characteristics of the study population.

\begin{tabular}{cccc}
\hline & $\begin{array}{c}\text { Hypertensives } \\
\text { Mean } \pm \text { SD }\end{array}$ & $\begin{array}{c}\text { Normotensives } \\
\text { Mean } \pm \text { SD }\end{array}$ & $\mathrm{p}$ \\
\hline Number $(\mathrm{N})$ & $31(10 \mathrm{M} / 21 \mathrm{~F})$ & $31(10 \mathrm{M} / 21 \mathrm{~F})$ & \\
Age (years) & $45 \pm 9$ & $42 \pm 9$ & 0.231 \\
Weight $(\mathrm{kg})$ & $83.3 \pm 11.8$ & $77.0 \pm 12.1$ & $\mathbf{0 . 0 3 7}$ \\
Height $(\mathrm{cm})$ & $166 \pm 5$ & $166 \pm 8$ & 0.849 \\
BMI (kg/m $)$ & $30.39 \pm 4.19$ & $28.03 \pm 4.19$ & 0.027 \\
SBP $(\mathrm{mmHg})$ & $142 \pm 13$ & $118 \pm 9$ & $<0.001$ \\
DBP $(\mathrm{mmHg})$ & $91 \pm 9$ & $76 \pm 7$ & $<0.001$ \\
HR (bpm) & $73 \pm 11$ & $67 \pm 12$ & $\mathbf{0 . 0 3 3}$
\end{tabular}

BMI: Body Mass Index; SBP: Systolic Blood Pressure; DBP: Diastolic Blood Pressure; HR: Heart Rate; SD: Standard Deviation. 


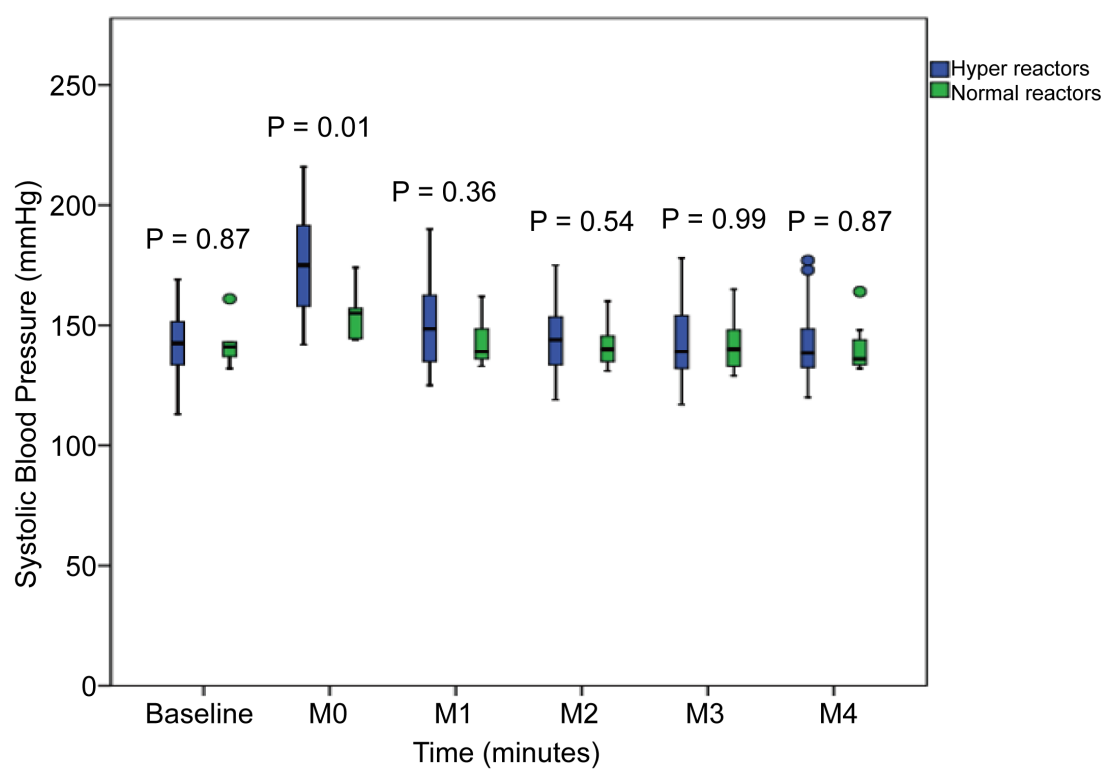

Figure 1. Systolic Blood pressure variation at baseline and during the cold pressor test between hyper reactors and normal reactors among hypertensive subjects.

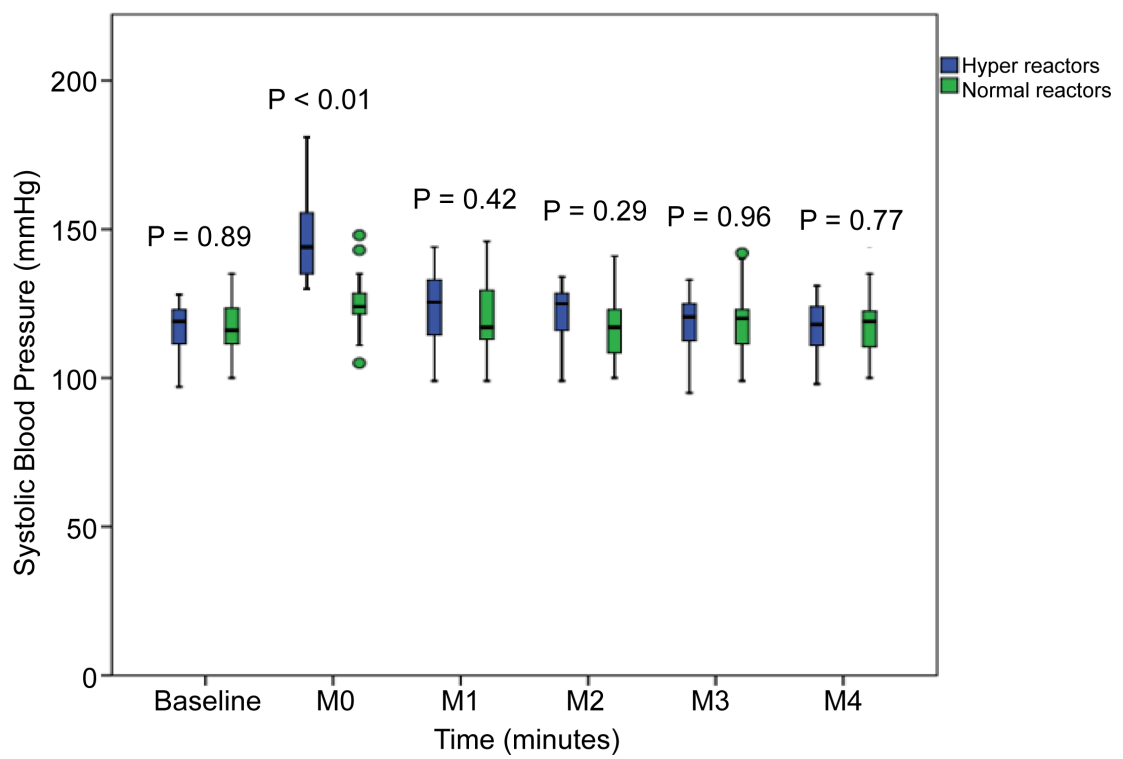

Figure 2. Systolic Blood pressure variation at baseline and during the cold pressor test between hyper reactors and normal reactors among normotensive subjects.

among both hypertensive and normotensive subjects. We can see that immediately after cessation of cold exposure, SBP increased significantly in hyper-reactors compared to normo-reactors in both groups (176 \pm 20 vs. $154 \pm 11$, $\mathrm{p}=0.01$ and $148 \pm 17$ as against $125 \pm 11, \mathrm{p}<0.001$, respectively for hypertensives and normotensives). SBP stayed higher in hyper-reactors up to 2 minutes after cold exposure, but the difference was not statistically significant. Similarly, Figure 3 and Figure 4 show that DBP, 0 minute after stopping stress exposure was statistically higher in hyper reactors than in normal reactors (111 \pm 13 vs. 99 


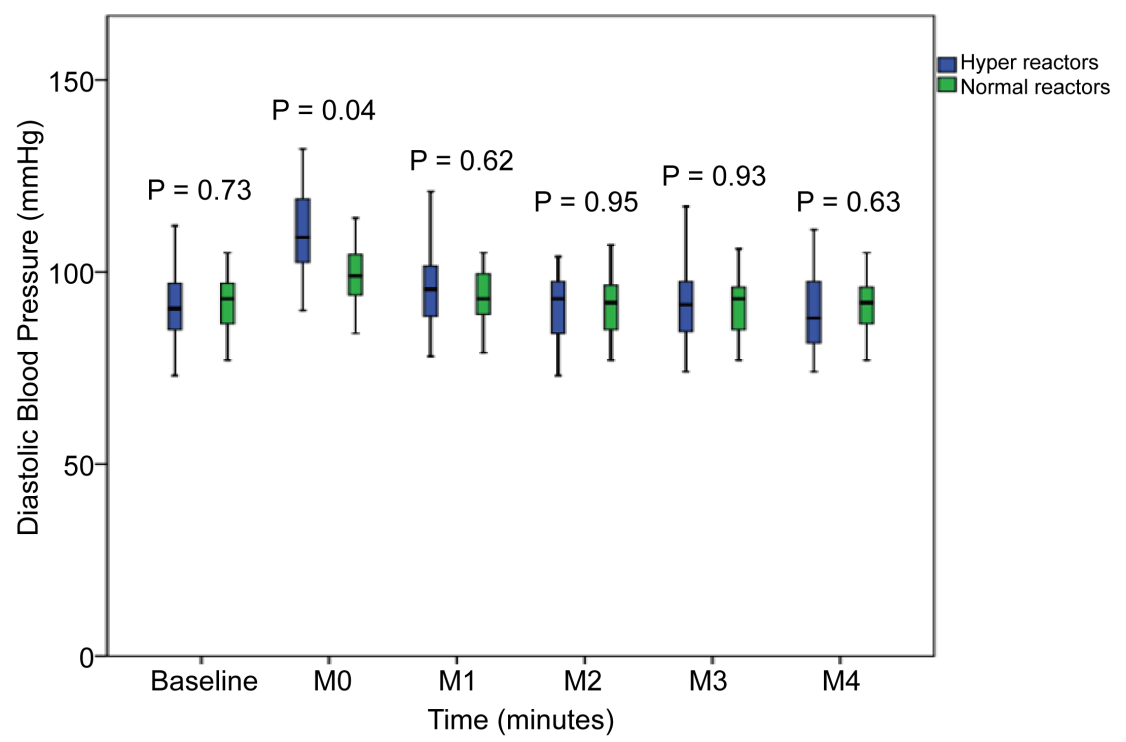

Figure 3. Diastolic Blood pressure variation at baseline and during the cold pressor test between hyper reactors and normal reactors among hypertensive subjects.

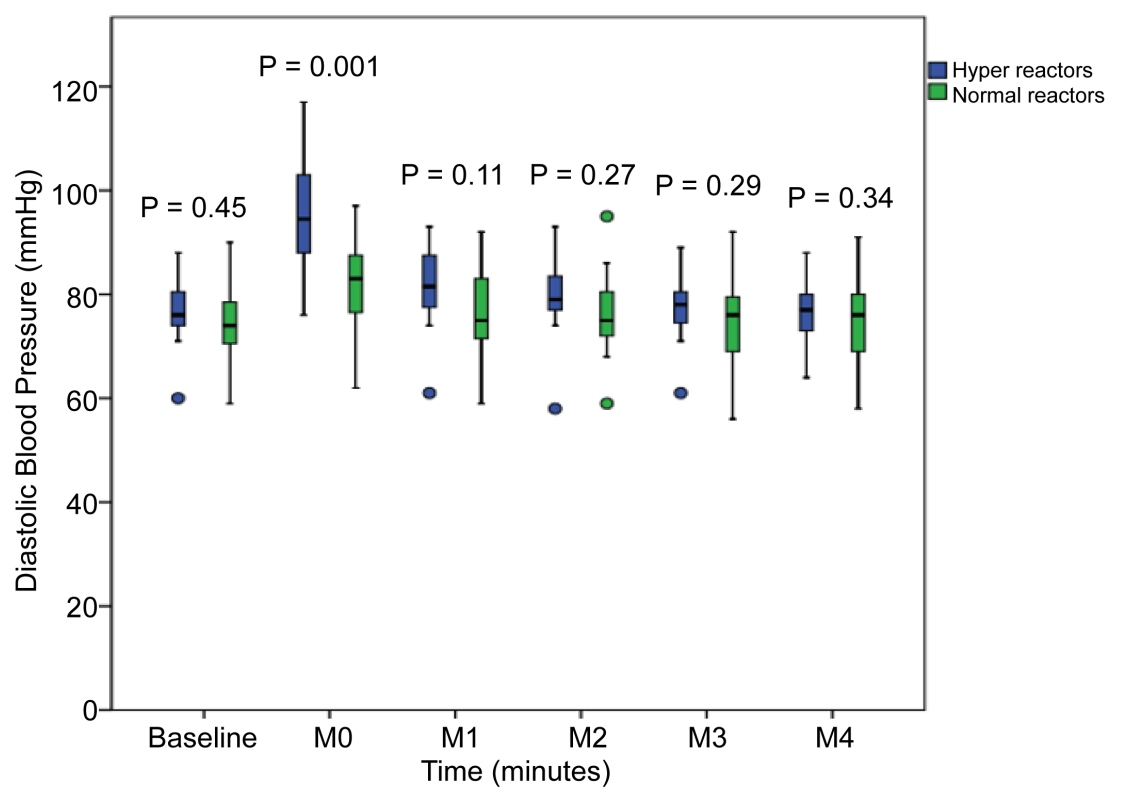

Figure 4. Diastolic Blood pressure variation at baseline and during the cold pressor test between hyper reactors and normal reactors among normotensive subjects.

$\pm 10, \mathrm{p}=0.04$ and $95 \pm 11$ vs. $81 \pm 10 ; \mathrm{p}=0.001$ in hypertensive and normotensive patients respectively). However, while DBP remained higher, but not statistically significant in the hypertensive hyper-reactors up to 2 minutes after the stress, the difference persisted up to the 4 th minute after the stress between the normotensive hyper reactors and normal reactors. The hyper reactors of the two groups took significantly longer to recover their basic BP than the normal reactors $(2.1 \pm 0.9$ vs. $1.1 \pm 0.4$ minutes, $\mathrm{p}=0.01$ and $1.9 \pm 1.0$ vs. $1.3 \pm 0.5$ minutes, $\mathrm{p}=0.03$ respectively in hypertensive and normotensive). 


\section{Discussion}

We performed this study to consider the variation of BP in African black subjects under stress. The cold test leads to a stimulation of the cutaneous thermo receptors and nociceptors. Thermal and nociceptive afferents (fibers A $\delta$ and $\mathrm{C}$ ) penetrate the spinal cord through the posterior horn and then decussate towards the contralateral side to follow the spinothalamic pathway. The latter reaches the thalamus and also sends collaterals towards the reticulated substance. These collaterals stimulate the vasomotor center at the level of the spinal bulb, which leads to a discharge of the sympathetic nervous system towards the heart and the blood vessels [7]. This results in significant variations in hemodynamic parameters, resulting in an increase in blood pressure due to peripheral vasoconstriction and an increase in cardiac output secondary to an acceleration of the heart rate [8]. Hyper reactors in the cold test have higher plasma concentrations of catecholamines and renin and are prone to be hypertensive as shown by several authors [5] [9]. Due to the greater sympathetic activity in the black subject, it is more reactive than cold test [10] [11].

The results of this study are consistent with those of Pramanik et al., Mishra et al., And Elfakharany et al., Who found a significant increase in SBP and DBP after the cold test [6] [12] [13]. Elfakharany et al., as well as found that BP was significantly higher in hyper reactors compared to normal reactors [13]. The vascular hyper reactivity which is several years before the appearance of the essential hypertension persists even after the development of the disease as we have observed in the hypertensive subjects. However, not all of them had vascular hyper reactivity because the sympathetic system is not the only pathophysiological mechanism involved in the genesis of hypertension, even though it is one of the main factors [14].

Stress is associated with increased sympathetic pressure, but in normal subjects it drops rapidly after elimination of the stress factor. On the other hand, BP longer remains elevated in individuals predisposed to have hypertension due to the inability of their autonomous nervous system to rapidly decrease BP [13]. In our study, we observed that the hyper reactors took significantly more time to recover their basic BP than the normal reactors, which is consistent with the findings of Pramanik et al. in 2009 [6]. The vascular hyper responsiveness to the cold test would therefore be a predictive factor of the HBP.

\section{Conclusion}

The black Cameroonian hyper reactors in the cold test take significantly longer to recover their basic BP. They are predisposed to develop hypertension if they are not yet affected. This again raises the question of the importance of the cold test in the prediction of essential hypertension.

\section{Competing Interests}

The authors declare no competing interest. 


\section{Authors' Contribution}

Sylvie Ndongo Amougou, Hamadou Ba and Dieudonné Danwe designed the study. Sylvie Ndongo Amougou, Hamadou Ba, Dieudonné Danwe, Chris Nadège Nganou-Gnindjio and Christian Ngongang Ouankou carried out the study. Dieudonné Danwe, Liliane Kuate Mfeukeu and Jérome hilaire Boomhbi contributed to the statistical analysis. Samuel Kingue contributed by overseeing the whole study. All authors have read and agreed to the final version of this manuscript.

\section{Acknowledgements}

Our gratitude goes to the staff of the Yaounde Teaching Hospital and to the Department of Internal Medicine of the Faculty of Medicine and Biomedical Sciences of the University of Yaoundé I.

\section{References}

[1] OMS (2015) Maladies Cardiovasculaires. WHO. http://www.who.int/mediacentre/factsheets/fs317/fr/

[2] Kearney, P.M., Whelton, M., Reynolds, K., Muntner, P., Whelton, P.K. and He, J. (2005) Global Burden of Hypertension: Analysis of Worldwide Data. The Lancet, 365, 217-223.

[3] Bolívar, J.J. (2013) Essential Hypertension: An Approach to Its Etiology and Neurogenic Pathophysiology. International Journal of Hypertension, 2013, Article ID: 547809. https://doi.org/10.1155/2013/547809

[4] Wood, D.L., Sheps, S.G., Elveback, L.R. and Schirger, A. (1984) Cold Pressor Test as a Predictor of Hypertension. Hypertension, 6, 301-306.

https://doi.org/10.1161/01.HYP.6.3.301

[5] Flaa, A., Eide, I.K., Kjeldsen, S.E. and Rostrup, M. (2008) Sympathoadrenal Stress Reactivity Is a Predictor of Future Blood Pressure: An 18-Year Follow-Up Study. Hypertension, 52, 336-341.

[6] Pramanik, T., Regmi, P., Adhikari, P. and Roychowdhury, P. (2009) Cold Pressor Test as a Predictor of Hypertension. The Journal of Tehran University Heart Center, 3, 177-180.

[7] Nakamura, T., Kawabe, K. and Sapru, H.N. (2008) Cold Pressor Test in the Rat: Medullary and Spinal Pathways and Neurotransmitters. American Journal of Physiology-Heart and Circulatory Physiology, 295, 1780-1787.

https://doi.org/10.1152/ajpheart.646.2008

[8] Yamamoto, K., Iwase, S. and Mano, T. (1992) Responses of Muscle Sympathetic Nerve Activity and Cardiac Output to the Cold Pressor Test. Japanese Journal of Physiology, 42, 239-252. https://doi.org/10.2170/jjphysiol.42.239

[9] Kasagi, F., Akahoshi, M. and Shimaoka, K. (1995) Relation between Cold Pressor Test and Development of Hypertension Based on 28-Year Follow-Up. Hypertension, 25, 71-76. https://doi.org/10.1161/01.HYP.25.1.71

[10] Calhoun, D.A., Mutinga, M.L., Collins, A.S., Wyss, J.M. and Oparil, S. (1993) Normotensive Blacks Have Heightened Sympathetic Response to Cold Pressor Test. Hypertension, 22, 801-805. https://doi.org/10.1161/01.HYP.22.6.801

[11] Kelsey, R.M., Patterson, S.M., Barnard, M. and Alpert, B.S. (2000) Consistency of 
Hemodynamic Responses to Cold Stress in Adolescents. Hypertension, 36, 1013-1017. https://doi.org/10.1161/01.HYP.36.6.1013

[12] Mishra, S., Manjareeka, M., Mishra, J. (2012) Blood Pressure Response to Cold Water Immersion Test. International Journal of Biology, Pharmacy and Allied Sciences, 1, 1483-1491.

[13] Elfakharany, A.T., El Azab, D.R. and Khaled, S.A.A. (2016) Response to Cold Pressor Test in Normotensive Adult Females. International Journal of Advanced Research in Biological Sciences, 3, 219-224.

https://doi.org/10.22192/ijarbs.2016.03.10.030

[14] Beevers, D.G. and Lip, G.Y.H. (2007) Pathophysiology of Hypertension. In: Beevers, D.G., Lip, G.Y.H. and O’Brien, E., Eds., ABC of Hypertension, 5th Edition, Malden, Mass, BMJ Books/Blackwell, Oxford, 12-16. 